\title{
Mortality in Coronary Care Unit of a Tertiary Level Hospital of Bangladesh
}

\author{
Md. Zahid Alam ${ }^{1}$, Shabnam Jahan Hoque ${ }^{2}$, Md. Jubaidul Islam³ ${ }^{3}$ Mohammad Shakhawat Hossain ${ }^{3}$, \\ Aparna Rahman ${ }^{3}$, AKM Mohibullah $^{4}$
}

\begin{abstract}
:
Background and objectives: Cardiovascular disease is the most common cause of death worldwide and Coronary Care Unit (CCU) plays a central role in reducing this mortality. Currently the data on mortality in CCU is very limited in our country. Our purpose of this study to provide data on mortality so that we can focus and improve the factors determining deaths in CCU.

Methodology: The data of all death cases admitted in the CCU of a tertiary level hospital between 1 January 2016 and 31 December 2017 were included for assessing the data on demography, diagnosis, and comorbidities at the time of death.
\end{abstract}

Results: Among 802 cases admitted in CCU in two years, 40 patients died (5\%). Male was $55 \%$ and female was $45 \%$. Most of the death occurred in their $6^{\text {th }}$ decade of life, due to Non-ST-Elevation Myocardial Infarction (NSTEMI) and sepsis, within 24-hour of CCU admission.Common associated co-morbidities were DM $(75 \%)$, hypertension (42.5\%), CKD (27.5\%), and hypokalemia (12.5\%).

Conclusions: The death rate is much lower in our CCU in comparison to global rate. The common cause of death is still NSTEMI. The common co-morbidities we found are DM, hypertension and CKD. Most of the deathsoccurred within 24-hour of admission.

Key words: Coronary Care Unit, Mortality, NSTEMI

\section{Introduction:}

Cardiovascular death is still the highest cause of death worldwide. ${ }^{1}$ Taking this critical situation under consideration, the idea of coronary care unit (CCU)was first introduced in early 1960s by the British Thoracic Society primarily in attempt to reduce the mortality of acute myocardial infarction (MI). Soon it was observed that patients with acute $\mathrm{MI}$ treated in CCU had better prognosis than those treated in general wards, mainly due to preventing fatal ventricular arrhythmias by early detection with continuous monitoring.In the late 1960s, it was shown that aggressive medical therapy in the CCU seemed to

1. Associate Professor, Department of Cardiology, BIRDEM General Hospital, Shahbag, Dhaka, Bangladesh.

2. Assistant Professor, Department of Cardiology, BIRDEM General Hospital, Shahbag, Dhaka, Bangladesh.

3. Senior Medical Officer, Department of Cardiology, BIRDEM General Hospital, Shahbag, Dhaka, Bangladesh.

4. Professor, Department of Cardiology, BIRDEM General Hospital, Shahbag, Dhaka, Bangladesh.

Address of Correspondence: Md. Zahid Alam, Associate Professor, Department of Cardiology, BIRDEM, General Hospital, Shahbag, Dhaka, Phone: +880 1711406290, Email: ilazybear@yahoo.com reduce in-hospital mortality from $26 \%$ to $7 \% .{ }^{2}$ In recent decades, care in CCU has been improved a lot along with the high cost. For common people this is certainly a burden. Still the numbers and facilities of CCU in every country according to their demand is limited. ${ }^{3}$

No doubt, in limited resources countries like Bangladesh, the appropriate management of acute cardiac event is not available in most of the cities. However, in major cities of Bangladesh, there are many tertiary care hospitals capable of dealing with these emergencies. But due to lack of any admission criteria in CCU, department of cardiology has to deal with many non-cardiac emergencies also. ${ }^{4}$ BIRDEM General Hospital is a tertiary level hospital and, according to daily patient attendance, it is the largest diabetic hospital in the world. ${ }^{5}$ It has a 7-bed CCU with non-invasive facilities for acute cardiac emergencies. As diabetic patients have multiple co-morbidities and has higher risk for cardiac events than those who are nondiabetic, ${ }^{6-8}$ our CCU plays a central role in giving almost every kind of emergency management along with cardiac 
diseases. Here we conducted a retrospective observational study on mortality covering the year 2016-17. As there is no sufficient data on mortality in CCU in our country, our objective was to find out the major cause of death and associated co-morbidities, so that we can intensify our goal-directed management.

\section{Materials and methods:}

This retrospective observational study was carried out for the year 2016-17 in the CCU of BIRDEM General Hospital which is a tertiary level hospital in the center of capital of Bangladesh.Every death file and registration book of CCU was scrutinizedand data were collected in a predesigned data collection sheet. Information included was the subject's age, gender, date of admission (or date of transfer from other unit), date and time of death, primary cause of death, associated co-morbidities, and whether the primary cause of death cardiac or non-cardiac. All the relevant collected data were compiled on a master chart first. Then organized by using scientific calculated and standard statistical formulas, percentage was calculated to find out the proportion of the findings. Data entry and analysis were done using SPSS for windows version 22.0. Output of data and graphical representation was done using Microsoft Office chart and Microsoft-Word. The results were presented in tables, figures, diagrams etc.

\section{Results:}

In the year 2016-17, total 802 patients were admitted in the CCU. Among them, 40 patients (5.0\%) died during their stay in the $\mathrm{CCU}$.

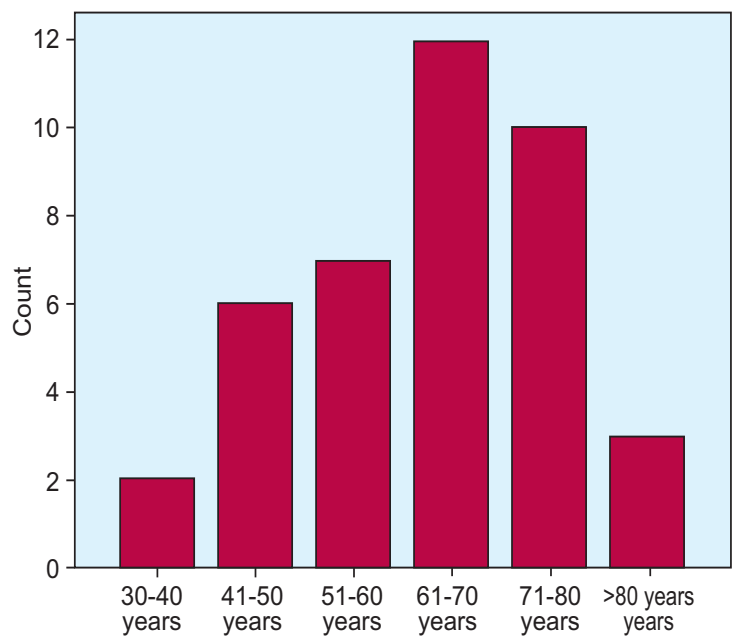

Fig.-1: Range of age

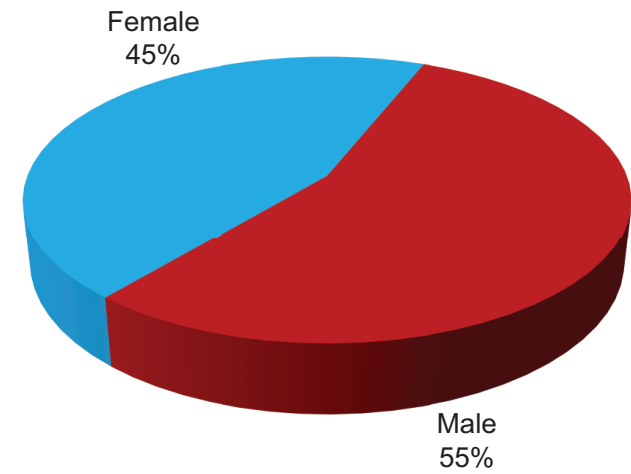

Fig.-2: Gender distribution.

It is shown that majority of the subjects were within $6^{\text {th }}$ decade of life and of male sex (Figure 1 and 2). Their main causes of death were acute anterior $\mathrm{Ml}$ and sepsis. Among 40 deceased subjects, $55 \%(n=22)$ were male, and $45 \%(n=18)$ were female. Most of the patients $(32.5 \%, n=13)$ died after 24 hours of stay (Figure 3 ). The time of death mostly between $12 \mathrm{pm}$ to $6 \mathrm{pm}$. (Figure 4). The common cause of death was Non-ST Elevation Myocardial Infarction (NSTEMI) $(30 \%, \mathrm{n}=$ 12). Sepsis remains in next position $(17.5 \%, n=7)$. Other causes of death were CKD $(15 \%, n=6)$, unstable angina $(10 \%, n=4)$, acute $\mathrm{Ml}$ anterior $(7.5 \%, \mathrm{n}=3)$, acute $\mathrm{Ml}$ inferior $(5 \%, n=2)$, acute stroke $(5 \%, n=2)$, dilated cardiomyopathy $(\mathrm{DCM})(2.5 \%, \mathrm{n}=1)$, ischemic cardiomyopathy $(\mathrm{ICM})(2.5 \%$, $\mathrm{n}=1)$, pneumonia $(2.5 \%, \mathrm{n}=1)$, and acute coronary syndrome (ACS) $(2.5 \%, n=1)$ (Figure 5$)$.

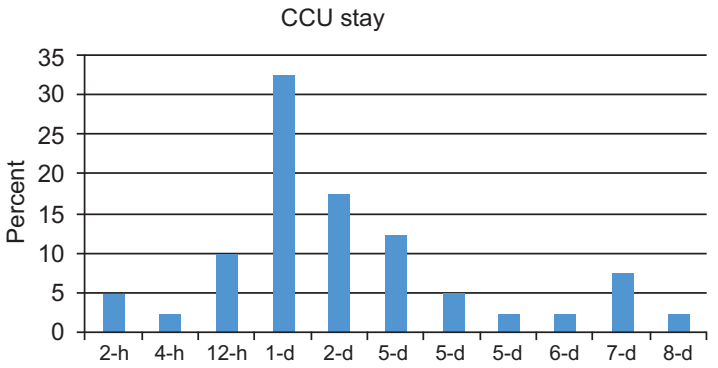

Fig.-3: Duration of CCU stay

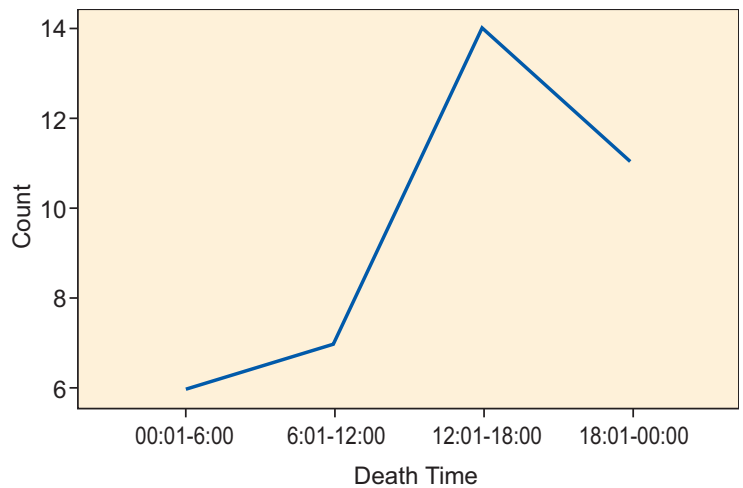

Fig.-4: Time of death 


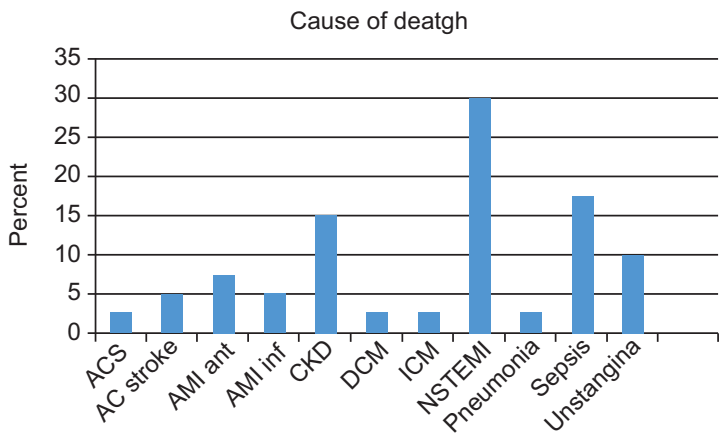

Fig.-5: Causes of death

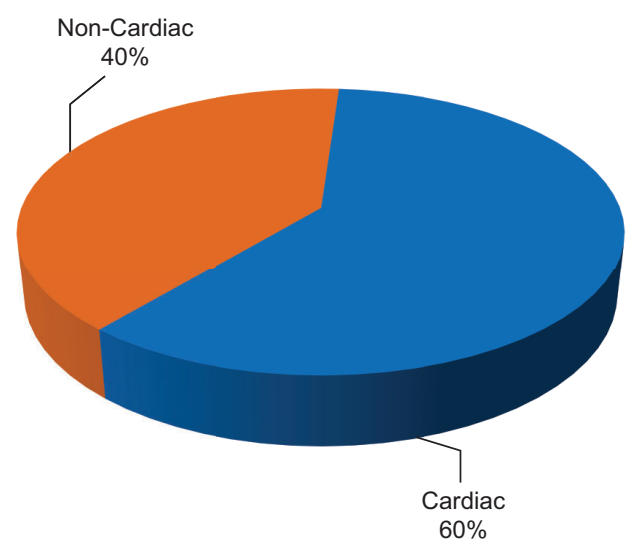

Fig.-6: Percentage of cardiac and non-cardiac cases

A good number of cases died from non-cardiac diseases $(40 \%, n=16)$ (Figure 6). Cardiac cause was $60 \%(n=$ 24).Directly admitted cases in CCU from Emergency Room (ER) were $40 \%(n=16)$, remaining $60 \%(n=24)$ were transferred in from other unit.

Major co-morbidities were DM $(75 \%, \mathrm{n}=30)$, hypertension $(42.5 \%, n=17)$, chronic kidney disease (CKD) $(27.5 \%, n=$ $11)$, and hypokalemia $(12.5 \%, n=5)$. However, there was much overlap among cases.

\section{Discussion:}

Important findings in our study are: Death rate in $\mathrm{CCU}$ is $5.0 \%$ and cause of death in CCU is still myocardial infarction as NSTEMI, and due to lack of admission criteria, a good number of non-cardiac deathswere observed.Death rate is higher in $6^{\text {th }}$ decade of life. Death due to NSTEMI was observed more in male than female $(17.5 \%, \mathrm{n}=7$ vs $12.5 \%$, $n=5)$.

Mortality is a very diverse matter globally due to a variety of reasons: Cause of death, associated morbidity, characteristics of patients (eg, age, sex, and family history), treatment received, etc. Despite much limited resource in our country, death rate in our CCU is much lower (5.0\%) in comparison to the developed world. The rate ranges from $5.6 \%$ to $20.6 \%$ in many developed countries. ${ }^{9-11}$ They have also many non-cardiac cases (eg, sepsis), ${ }^{9}$ but those cases were closely associated with cardiac reason (sepsis following cardiac surgery).

In our CCU, pattern of MI was mostly NSTEMI. This is largely because of associated DM. Because NSTEMI is commonly observed in diabetic patients worldwide. ${ }^{12-14}$ In our observation, male patients had more NSTEMI than females. The gender differences in death due to MI was also found in many larger studies in other part of the world. ${ }^{15-17}$ Some causes of death were labeled as ACS, because those cases died before getting the confirmatory investigations like cardiac markers (eg, Troponin-I) and before doing echocardiography. They were classified as ACS on the basis of clinical presentation (ie, new angina, increasing angina, and rest angina) and findings of electrocardiogram (ECG). ${ }^{18}$

The study findings that alarmed us are as follows: Most of the death occurred at or around first 24-hour of admission, between 12 to $6 \mathrm{pm}$, and of age group between 61 and 70 years. This is likely due to referral bias from other centers because we faced most admission in the morning and commonly fatal cases or cases with high morbidity were commonly referred to us. Certainly we need to intensify our management team during this period of time. Moreover, as the associated major co-morbidities are DM, CKD and hypertension, we have to strengthen the root of management of these patients with aggressive control of the diseases along with early identification of their complications.

There are many gross limitations in our study. First, we could not emphasize the background history of the patients that could be more helpful for us to identify the consequences of death, eg, glycemic control, compliance to regular follow up, and personal history (esp, tobacco use). Second, this is a single center based retrospective study. And third, because our hospital is a tertiary level hospital and specialized mainly on diabetes care, there is an obvious chance of referral bias.

The strength of our study are: First, to our knowledge, it is the largest published study in our country till date. Second, previously we had no authentic data about the common cause of death to give emphasis on the treatment. Third, with this study we can encourage and assure our young doctors about their competency and potency in treating critical cardiac patients because of much lower mortality in our CCU than that of many developed world. Fourth, this study proves that we need definite criteria for admission in CCU. Because the appropriate facilities of many CCU are scarce in our country. So it is clear that if non-cardiac cases 
will be admitted in CCU, critical cardiac cases who actually need management in CCU will be deprived from CCU care.

However, as we have no provision of invasive procedure like coronary angiogram and intervention, we believe we can improve our care in CCU more if we have these facilities.

\section{References:}

1. Cardiovascular diseases (CVDs) [Internet] 2017. Available from: http://www.who.int/mediacentre/ factsheets/fs317/en/

2. Katz JN, Becker RC. Evolution of the Coronary Care Unit: Past, Present,and Future. In: Jeremias A, Brown DL, editors. Cardiac Intensive Care. $2^{\text {nd }}$ ed. Philadelphia. Saunders Elsvier; 2010. P.1-9

3. Weiner SD, Rabbani LE. Cardiac Intensive Care Unit Admission Criteria. [Internet] 2015. [updated 2015 Jun 21]. Available from: https://clinicalgate.com/cardiacintensive-care-unit-admission-criteria/

4. Alam MZ, Rahman A, Ahsan HMN, Hoque SJ, Khan MMZA. Characteristics of Disease Profile of Hospitalized Patients Referred to the Department of Cardiology in a Tertiary Care Hospital. Neurosciences Bangladesh 2017;3(2):33-7.

5. BIRDEM [Internet] 2018 Feb 3. Available from: https:/ len.wikipedia.org/wiki/BIRDEM

6. Cardiovascular Disease and Risk Management. Diabetes Care 2015; 38(1): S49-S57.

7. Pearson ER, McCrimmon RA. Diabetes Mellitus. In: Walker BR, Colledge NR, Penman ID, Ralston SH, editors. Davidson's Principle and Practice of Medicine. $22^{\text {nd }}$ ed. Edinburgh. Churchill Livingstone Elsvier, 2014. P.798-836.

8. Laakso M. Cardiovascular Disease in Type 2 Diabetes From Population to Man to Mechanisms. Diabetes Care 2010;33(2): 442-9.

9. Ratcliffe JA, Wilson E, Islam S, Platsman Z, Leou K, Williams G, et al. Mortality in The Coronary Care Unit. Coron Artery Dis. 2014;25(1):60-5.
10. Chua TS, Koo C, Tan AT, Ho CK. Mortality trends in the coronary care unit. Ann Acad Med Singapore 1990;19(1):3-8.

11. Dogan S, Dursun H, Can H, Ellidokuz H, Kaya D. Longterm assessment of coronary care unit patient profile and outcomes: analyses of the 12-years patient records. Turk J Med Sci 2016; 46: 801-6.

12. Awad HH, Tisminetzky M, Metry D, McManus D, Yarzebski J, Gore JM, et al. Magnitude, Treatment, and Impact of Diabetes Mellitus in Patients Hospitalized with Non-ST Segment Elevation Myocardial Infarction: A Community-Based Study. Diab Vasc Dis Res 2016;13(1): 13-20.

13. Rafique I, Khan AN. Frequency of Diabetes in Non ST Elevation Myocardial infarction. Pak Armed Forces Med J 2017; 67(2): 207-10.

14. Ratanasumawong K, Boonyaratavej S, Srimahachota S, Boonsom W, Tungsubutra W, Sanguanwong S. Diabetes mellitus and non-ST elevation myocardial infarction in Thai ACS Registry.J Med Assoc Thai 2007;90(I):51-7.

15. Moshki M, Zareie M, Hashemizadeh H. Sex differences in Acute Myocardial Infarction. Nurs Midwifery Stud. 2015; 4(1): e22395.

16. Heer T, Schiele R, Schneider S, Gitt AK, Wienbergen $H$, Gottwik M, et al. Gender differences in acute myocardial infarction in the era of reperfusion (the MITRA registry). Am J Cardiol 2002;89(5):511-7.

17. Yang HY, Huang JH, Hsu CY, Chen YJ. Gender Differences and the Trend in the Acute Myocardial Infarction: A 10-Year Nationwide Population-Based Analysis. Sci World J [Internet] 2012. Available from: https://www.hindawi.com/journals/tswj/2012/184075/

18. Newby DE, Grubb NR, Bradbury A. Cardiovascular Disease: Acute Coronary Syndrome. In: Walker BR, Colledge NR, Penman ID, Ralston SH, editors. Davidson's Principle and Practice of Medicine. 22 ${ }^{\text {nd }}$ ed. Edinburgh. Churchill Livingstone Elsvier, 2014. P.589-93. 